\title{
Viscosities of Liquid Fluorocompounds
}

\author{
Mara G. Freire, ${ }^{\dagger}$ Abel G. M. Ferreira, ${ }^{\ddagger}$ Isabel M. A. Fonseca, ${ }^{\ddagger}$ Isabel M. Marrucho, ${ }^{\dagger}$ and João A. P. Coutinho*, ${ }^{*}$ \\ CICECO, Departamento de Química, Universidade de Aveiro, 3810-193 Aveiro, Portugal, and Departamento de Engenharia \\ Química, Faculdade de Ciências a Tecnologia, Universidade de Coimbra, Polo II, Pinhal de Marrocos, 3030-290 Coimbra, Portugal
}

\begin{abstract}
In spite of their interest, viscosities of fluorocarbon compounds are scarce, and the available data are unreliable and of poor accuracy. In this work, viscosity measurements of linear, cyclic, aromatic, and $\alpha$-substituted perfluorocarbons were carried out in the temperature range between (298.15 and 318.15) K using an Ubbelohde viscometer. The experimental results show that fluorinated compounds present viscosities considerably higher than their hydrocarbon homologues as expected. The viscosities increase from linear to aromatic to cyclic perfluorocarbons and within each family with the molecule size. The $\alpha$-fluorine substitution by bromine increases the fluorocarbon viscosity due to the molecular weight increase. The Sastri-Rao method, a group contribution method for the liquid viscosity prediction, was applied for all the fluorocarbons where the viscosity was experimentally measured in this work. Using the new experimental data from this work, new group contribution values are proposed for fluorocarbon compounds allowing for a reduction of the average relative deviation from $12.0 \%$ to $1.3 \%$.
\end{abstract}

\section{Introduction}

Fluorocarbons (FCs) and perfluorocarbons (PFCs) are petroleum-based compounds synthesized by substitution of the hydrogen atoms of hydrocarbons by fluorine. PFCs are biochemically stable due to their strong intramolecular forces and their steric protection afforded by the fluorine atoms. Besides, they present weak intermolecular interactions that confer them the ability to dissolve large quantities of gases. ${ }^{1-8}$ The atypical physicochemical properties of PFCs make them extremely interesting from the scientific point of view, and they have given rise to the development of valuable applications in various fields. They are being extensively studied as surfactants in supercritical solvents, substitutes for chlorinated solvents, environmental probes to determine the exchanges between the atmosphere and natural waters, anticorrosive and antifriction components, flameretardants, and water repellents. It is, however, in the biomedical field that their most relevant applications are found. PFCs are currently being used in tissue oxygenation as blood substitutes, as antitumural agents, perfusates for isolated organs, gas carriers in eye surgery, diagnostic imaging agents, lubrication and cushioning for articular disorders, cell culture media, and drug delivery systems. ${ }^{2-13}$

The various novel applications which fluorocompounds are finding are directly related to the unique thermophysical properties displayed by these compounds. Given the capacity of fluorocarbons to dissolve large volumes of gases such as carbon dioxide ${ }^{8}$ and oxygen, ${ }^{2-6}$ one of their interesting applications is as oxygen carriers both as synthetic blood substitutes ${ }^{9}$ and in aerobic cells culture media. ${ }^{11,12}$ These applications, where mass-transfer operations are involved, require accurate thermophysical data of pure liquid fluorocompounds. Fluorocarbon viscosities are particularly important as they determine the rheological behavior in their emulsion formulations ${ }^{9}$ and the gases permeability in the fluid controlling the mass transfer rates.

\footnotetext{
* To whom correspondence should be addressed. E-mail: jcoutinho@dq.ua.pt.

Universidade de Aveiro.

Universidade de Coimbra.
}

Although other thermophysical properties of FCs have been recently reported in the literature, such as densities, ${ }^{14}$ vapor pressures, ${ }^{14}$ and surface tensions, ${ }^{15}$ the available viscosity data of liquid fluorocarbons are still scarce and of low accuracy. ${ }^{16-18}$ In the framework of our project concerning the aeration improvement of multiphase biological reactors, ${ }^{19}$ it was found to be important to have new and high-quality viscosity data for these compounds that could only be achieved due to the highpurity compounds available nowadays. In this work, kinematic viscosities were measured, as a function of temperature, using an Ubbelohde viscometer for linear, cyclic, aromatic, and one $\alpha$-substituted PFC.

Experimental measurements are time consuming and often expensive, thus promoting the development and application of correlations and/or models. The Satri-Rao method (1992), ${ }^{20-22}$ a group contribution method commonly used to estimate low-temperature liquid viscosities, was here applied for all the fluorocarbons where the viscosity was experimentally measured. Original values for the functional group contributions were taken from the open literature ${ }^{20-22}$ when available, and new values for the group contributions are also proposed in this work, due to the availability of more recent and reliable experimental data.

\section{Experimental Section}

Materials. Viscosities were measured for four $n$-perfluoroalkanes, two cyclic and two aromatic perfluorocompounds, and one $\alpha$-substituted fluorooctane. The linear 1,1,1,2,2,3,3,4,4,5,5,6, 6,6-tetradecafluorohexane, $\mathrm{C}_{6} \mathrm{~F}_{14}$ [CAS number 355-42-0], the $1,1,1,2,2,3,3,4,4,5,5,6,6,7,7,8,8,8$-octadecafluorooctane, $\mathrm{C}_{8} \mathrm{~F}_{18}$ [CAS number 307-34-6], and the 1,1,1,2,2,3,3,4,4,5,5,6,6,7,7,8,8,9, 9,9-eicosafluorononane, $\mathrm{C}_{9} \mathrm{~F}_{20}$ [CAS number 375-96-2], were obtained from Fluorochem with purities verified by Gas Chromatography (GC) of $(99.11,98.36$, and 99.18) wt \%, respectively. The 1,1,1,2,2,3,3,4,4,5,5,6,6,7,7,7-hexadecafluoroheptane, $\mathrm{C}_{7} \mathrm{~F}_{16}$ [CAS number 335-57-9], was from Apollo Scientific with a purity of 99.92 wt $\%$. The cyclic $1,1,2,2,3,3,4,4,5$, 
5,6-undecafluoro-6-(trifluoromethyl)cyclohexane, $\mathrm{C}_{7} \mathrm{~F}_{14}$ [CAS number 355-02-2], was from Apollo Scientific with a purity of $99.98 \mathrm{wt} \%$, and the $1,1,2,2,3,3,4,4,4 \mathrm{a}, 5,5,6,6,7,7,8,8,8 \mathrm{a}$-octadecafluorodecalin, $\mathrm{C}_{10} \mathrm{~F}_{18}$ [CAS number 306-94-5], was from Flutec with a purity of $99.88 \mathrm{wt} \%$. The aromatic 1,2,3,4,5,6hexafluorobenzene, $\mathrm{C}_{6} \mathrm{~F}_{6}$ [CAS number 392-56-3], was obtained from Fluorochem, and the 1,2,3,4,5-pentafluoro-6-(trifluoromethyl)benzene, $\mathrm{C}_{7} \mathrm{~F}_{8}$ [CAS number 434-64-0], from Apollo Scientific with purities of (99.99 and 99.90) wt \%, respectively. The 1-bromo-1,1,2,2,3,3,4,4,5,5,6,6,7,7,8,8,8-heptadecafluorooctane, $\mathrm{C}_{8} \mathrm{~F}_{17} \mathrm{Br}$ [CAS number 423-55-2], was from Apollo Scientific presenting a purity of $99.90 \mathrm{wt} \%$.

The fluorocarbons were used without any further purification, with the exception of $\mathrm{C}_{10} \mathrm{~F}_{18}$ that was purified by passage through a silica column (ca. 10 times) according the suggestions from Gaonkar and Newman ${ }^{23}$ and Goebel and Lunkenheimer. ${ }^{24}$ The initial purity of this compound was $97.75 \mathrm{wt} \%$, and after purification, it was $99.88 \mathrm{wt} \%$, as determined by gas chromatography (GC).

Experimental Procedure. The purity of each compound was analyzed by GC with a Varian Gas Chromatograph CP 3800 with a flame ionization detector. Chromatographic separations were accomplished with a Varian CP-Wax 52CB column with an internal diameter of $0.53 \mathrm{~mm}$ and equipped with Coating WCot fused silica.

The experimental viscosity measurements were carried out for each fluorocompound in the temperature range from (298.15 to 318.15$) \mathrm{K}$ and at atmospheric pressure. The kinematic viscosities, $v$, were measured using an Ubbelohde viscometer with a Schott-Geräte automatic measuring unit model AVS470 , for which the uncertainty in the flow time of measurement is $\pm 0.01 \mathrm{~s}$. The viscometer AVS 470 is coupled to a Visco System, a Visco pump II, and a head controller bath CT52, all from SCHOTT instruments. The liquid under measurement was kept thermostatized in the glass capillary by means of a water bath. The temperature was measured with a platinum resistance probe, with an uncertainty of $\pm 0.01 \mathrm{~K}$, coupled with a GW Instek Dual Display Digital Multimeter GDM-845. The viscometer constant was validated and checked with pure compounds (methanol and propan-1-ol from (298.15 to 323.15) K) viscosity measurements. Furthermore, kinetic energy corrections were applied to the experimental kinematic viscosity data.

For each sample at a specific temperature, at least five individual measurements were performed, allowing the determination of an average viscosity value as well as the associated expanded uncertainty of the experimental measurements. ${ }^{25}$

\section{Results and Discussion}

Viscosity Measurements. The viscosities were measured in the temperature range between (298.15 and 318.15$) \mathrm{K}$ and at atmospheric pressure for four linear $n$-perfluoroalkanes $\left(\mathrm{C}_{6} \mathrm{~F}_{14}\right.$, $\left.\mathrm{C}_{7} \mathrm{~F}_{16}, \mathrm{C}_{8} \mathrm{~F}_{18}, \mathrm{C}_{9} \mathrm{~F}_{20}\right)$, two cyclic perfluorocarbons $\left(\mathrm{C}_{7} \mathrm{~F}_{14}\right.$ and $\left.\mathrm{C}_{10} \mathrm{~F}_{18}\right)$, two aromatic perfluorocarbons $\left(\mathrm{C}_{6} \mathrm{~F}_{6}\right.$ and $\left.\mathrm{C}_{7} \mathrm{~F}_{8}\right)$, and one $\alpha$-substituted fluorocompound $\left(\mathrm{C}_{8} \mathrm{~F}_{17} \mathrm{Br}\right)$. The kinematic viscosity was measured with the equipment described above and then converted to dynamic or absolute viscosity multiplying the kinematic viscosity by the corresponding density value at each temperature and for each individual compound. The pure liquid densities were taken from Dias et al. ${ }^{14,27,28}$ The dynamic viscosity data were compared with the literature data whenever possible. ${ }^{16-18}$ The relative deviations between the dynamic viscosities measured in this work and those reported by other authors are presented in Figure 1. Deviations in the range (5 to 13) $\%$ are observed and are fairly constant in the studied

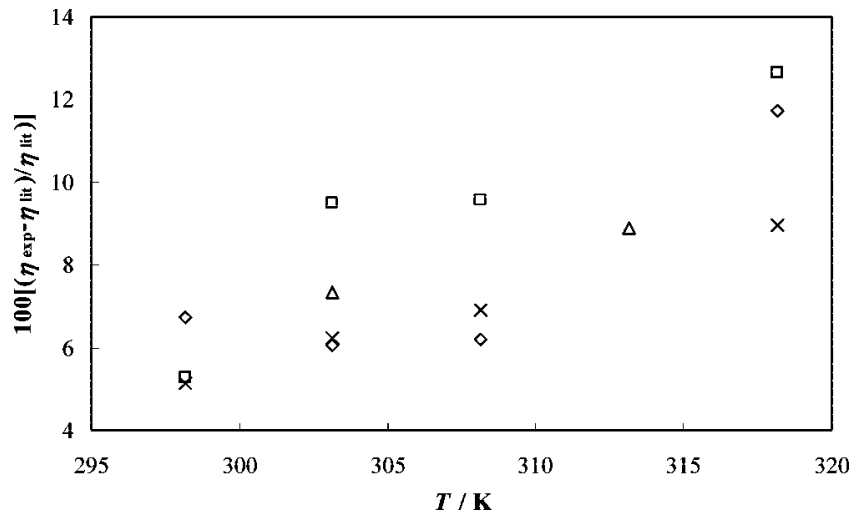

Figure 1. Relative deviations between the experimental viscosity data of this work and those reported in the literature: $\times, \mathrm{C}_{7} \mathrm{~F}_{16},{ }^{16} \Delta, \mathrm{C}_{6} \mathrm{~F}_{14},{ }^{17} \diamond$, $\mathrm{C}_{7} \mathrm{~F}_{14},{ }^{18} \square, \mathrm{C}_{10} \mathrm{~F}_{18 \cdot}{ }^{18}$

temperature interval, with the exception of the highest temperature. Unfortunately, due to the lack of experimental data, no direct comparison between the different authors is possible. It should be mentioned that the available data are 50 to 60 years old and of poor accuracy, and the compounds used were of lower purity. ${ }^{16-18}$ Moreover, the dynamic viscosity requires density data of the compounds under study, and the authors of the previous studies obtained these from experimental measurements using pycnometers. Thus, compounds of higher purity, the use of accurate fluorocarbons densities, ${ }^{14,27,28}$ and the automated viscometer allow more accurate measurements of PFC and FC dynamic viscosities.

Kinematic and dynamic viscosity results for the linear, cyclic, aromatic, and substituted FCs are reported in Tables 1 and 2. The data present a good precision, with small associated expanded uncertainties for each compound and at each temperature. Comparing the obtained dynamic viscosities for perfluorocarbon compounds with those exhibited by the corresponding hydrocarbons, it can be concluded that fluorocarbon dynamic viscosities are higher than for the corresponding hydrocarbons, with $\mathrm{C}_{6} \mathrm{~F}_{14}$ presenting a viscosity value close to $\mathrm{C}_{9} \mathrm{H}_{20}$ at room temperature. ${ }^{29}$ This behavior was also previously observed for the gaseous hydrocarbonated and perfluorinated methane and propane. ${ }^{30}$ In fact, the higher viscosities of PFCs related to their hydrocarbon analogues are the direct result of the PFC's higher molecular weight. ${ }^{22}$ The measured values of $n$-perfluoroalkane dynamic viscosities show that they are strongly dependent on the carbon number, similar to what is observed for hydrocarbons, but with a more pronounced temperature dependency, which is a reflection of their lower intermolecular forces when compared with the corresponding nonfluorinated molecules. ${ }^{29}$ Comparing the viscosity of $\mathrm{C}_{8} \mathrm{~F}_{17} \mathrm{Br}$ with the respective fully fluorinated octadecafluorooctane, it can be seen that the inclusion of a less electronegative and heavier heteroatom leads to an increase in the viscosity. ${ }^{31}$ For the cyclic and aromatic perfluorocompounds, the viscosities are also higher than for the $n$-perfluoroalkanes with the same carbon number. The highest PFC viscosities were observed for perfluorodecalin, a bicyclic compound. For all the families, the trend of increasing viscosities with the carbon number increase was observed. This is due to the fact that molecules with longer chains can move less freely, and the friction is therefore higher. From the results obtained, it is clear that the molecular structure is the major factor determining viscosity.

For all the FCs studied within this work, the viscosity temperature dependence for the experimental $20 \mathrm{~K}$ temperature 
Table 1. Experimental Kinematic $(\eta)$ and Dynamic Viscosity $(\eta)$ of $n$-Perfluoroalkanes and of the Substituted Fluoroalkane

\begin{tabular}{|c|c|c|c|c|c|}
\hline & $\mathrm{C}_{6} \mathrm{~F}_{14}$ & $\mathrm{C}_{7} \mathrm{~F}_{16}$ & $\mathrm{C}_{8} \mathrm{~F}_{18}$ & $\mathrm{C}_{9} \mathrm{~F}_{20}$ & $\mathrm{C}_{8} \mathrm{~F}_{17} \mathrm{Br}$ \\
\hline$T / \mathrm{K}$ & $\left(\mathrm{m}^{2} \cdot \mathrm{s}^{-1}\right)$ & $\left(\mathrm{m}^{2} \cdot \mathrm{s}^{-1}\right)$ & $\left(\mathrm{m}^{2} \cdot \mathrm{s}^{-1}\right)$ & $\left(\mathrm{m}^{2} \cdot \mathrm{s}^{-1}\right)$ & $\left(\mathrm{m}^{2} \cdot \mathrm{s}^{-1}\right)$ \\
\hline 303.15 & $3.97 \pm 0.04$ & $5.12 \pm 0.04$ & $6.562 \pm 0.004$ & $9.11 \pm 0.03$ & $9.96 \pm 0.04$ \\
\hline 308.15 & $3.72 \pm 0.01$ & $4.82 \pm 0.05$ & $6.081 \pm 0.002$ & $8.33 \pm 0.03$ & $9.05 \pm 0.05$ \\
\hline 313.15 & $3.57 \pm 0.02$ & $4.48 \pm 0.03$ & $5.652 \pm 0.003$ & $7.73 \pm 0.01$ & $8.37 \pm 0.02$ \\
\hline$T / \mathrm{K}$ & $(\mathrm{mPa} \cdot \mathrm{s})$ & $(\mathrm{mPa} \cdot \mathrm{s})$ & $(\mathrm{mPa} \cdot \mathrm{s})$ & $(\mathrm{mPa} \cdot \mathrm{s})$ & $(\mathrm{mPa} \cdot \mathrm{s})$ \\
\hline 298.15 & $0.700 \pm 0.004$ & $0.938 \pm 0.001$ & $1.256 \pm 0.001$ & $1.789 \pm 0.008$ & $2.038 \pm 0.007$ \\
\hline 303.15 & $0.659 \pm 0.007$ & $0.878 \pm 0.006$ & $1.157 \pm 0.001$ & $1.618 \pm 0.006$ & $1.895 \pm 0.007$ \\
\hline 308.15 & $0.612 \pm 0.002$ & $0.820 \pm 0.008$ & $1.057 \pm 0.001$ & $1.469 \pm 0.004$ & $1.711 \pm 0.008$ \\
\hline 313.15 & $0.583 \pm 0.004$ & $0.755 \pm 0.005$ & $0.975 \pm 0.001$ & $1.353 \pm 0.002$ & $1.572 \pm 0.004$ \\
\hline
\end{tabular}

${ }^{a}$ Expanded uncertainty with an approximate $95 \%$ level of confidence.

Table 2. Experimental Kinematic $(v)$ and Dynamic Viscosity $(\eta)$ of Cyclic and Aromatic Perfluorocompounds

\begin{tabular}{|c|c|c|c|c|}
\hline \multirow[b]{3}{*}{$T / \mathrm{K}$} & $\mathrm{C}_{7} \mathrm{~F}_{14}$ & $\mathrm{C}_{10} \mathrm{~F}_{18}$ & $\mathrm{C}_{6} \mathrm{~F}_{6}$ & $\mathrm{C}_{7} \mathrm{~F}_{8}$ \\
\hline & $10^{7}\left(\nu \pm \sigma^{a}\right)$ & $10^{7}\left(v \pm \sigma^{a}\right)$ & $10^{7}\left(v \pm \sigma^{a}\right)$ & $10^{7}\left(v \pm \sigma^{a}\right)$ \\
\hline & $\left(\mathrm{m}^{2} \cdot \mathrm{s}^{-1}\right)$ & $\left(\mathrm{m}^{2} \cdot \mathrm{s}^{-1}\right)$ & $\left(\mathrm{m}^{2} \cdot \mathrm{s}^{-1}\right)$ & $\left(\mathrm{m}^{2} \cdot \mathrm{s}^{-1}\right)$ \\
\hline 298.15 & $9.31 \pm 0.03$ & $28.03 \pm 0.02$ & $5.81 \pm 0.04$ & $5.88 \pm 0.01$ \\
\hline 303.15 & $8.43 \pm 0.04$ & $24.48 \pm 0.03$ & $5.35 \pm 0$ & $5.51 \pm 0.02$ \\
\hline 308.15 & $7.72 \pm 0.03$ & $21.59 \pm 0.04$ & $4.91 \pm 0.01$ & $5.16 \pm 0.01$ \\
\hline 313.15 & $7.22 \pm 0.04$ & $19.17 \pm 0.01$ & $4.50 \pm 0.03$ & $4.84 \pm 0.01$ \\
\hline 318.15 & $6.84 \pm 0.04$ & $17.09 \pm 0.02$ & $4.23 \pm 0.04$ & $4.57 \pm 0.01$ \\
\hline \multirow[b]{2}{*}{$T / \mathrm{K}$} & $\left(\eta \pm \sigma^{a}\right)$ & $\left(\eta \pm \sigma^{a}\right)$ & $\left(\eta \pm \sigma^{a}\right)$ & $\left(\eta \pm \sigma^{a}\right)$ \\
\hline & $(\mathrm{mPa} \cdot \mathrm{s})$ & $(\mathrm{mPa} \cdot \mathrm{s})$ & $(\mathrm{mPa} \cdot \mathrm{s})$ & $(\mathrm{mPa} \cdot \mathrm{s})$ \\
\hline 298.15 & $1.665 \pm 0.006$ & $5.412 \pm 0.004$ & $0.933 \pm 0.006$ & $0.977 \pm 0.001$ \\
\hline 303.15 & $1.495 \pm 0.006$ & $4.698 \pm 0.006$ & $0.853 \pm 0.008$ & $0.909 \pm 0.004$ \\
\hline 308.15 & $1.359 \pm 0.006$ & $4.120 \pm 0.008$ & $0.777 \pm 0.002$ & $0.846 \pm 0.002$ \\
\hline 313.15 & $1.261 \pm 0.007$ & $3.635 \pm 0.001$ & $0.707 \pm 0.005$ & $0.789 \pm 0.001$ \\
\hline 318.15 & $1.184 \pm 0.007$ & $3.222 \pm 0.004$ & $0.660 \pm 0.006$ & $0.740 \pm 0.001$ \\
\hline
\end{tabular}

${ }^{a}$ Expanded uncertainty with an approximate $95 \%$ level of confidence.

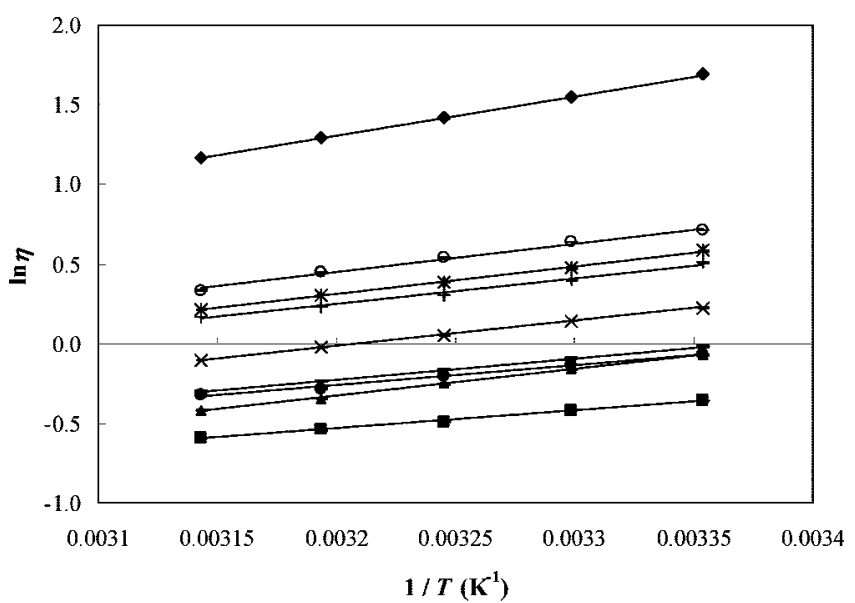

Figure 2. Arrhenius-type plot of viscosity ( $\mathrm{mPa} \cdot \mathrm{s}$ units) as a function of temperature: $\square, \mathrm{C}_{6} \mathrm{~F}_{14} ; \bullet, \mathrm{C}_{7} \mathrm{~F}_{16} ; \times, \mathrm{C}_{8} \mathrm{~F}_{18} ; *, \mathrm{C}_{9} \mathrm{~F}_{20} ; \mathrm{O}, \mathrm{C}_{8} \mathrm{~F}_{17} \mathrm{Br} ;+, \mathrm{C}_{7} \mathrm{~F}_{14}$; $\bullet, \mathrm{C}_{10} \mathrm{~F}_{18} ; \Delta, \mathrm{C}_{6} \mathrm{~F}_{6} ;-, \mathrm{C}_{7} \mathrm{~F}_{8}$.

range follows an Arrhenius-type law, as described by eq 1 and presented in Figure 2.

$$
\eta=\eta_{0} e \frac{E_{\eta}}{R T}
$$

where $\eta$ is the dynamic viscosity; $\eta_{0}$ is the pre-exponential factor, $E_{\eta}$ is the activation energy of each fluid; $R$ is the ideal gas constant; and $T$ is the temperature.
Table 3. Pre-exponential Factor ( $\ln \eta_{0}$, with $\eta_{0}$ and $\boldsymbol{\eta}$ in Pa $\cdot \mathrm{s}$ units) and Activation Energy-Ideal Gas Constant Coefficient $\left(E_{\eta} / R\right)$ Derived from Equation 1, Molecular Weight $\left(M_{\mathrm{r}}\right)$, and Normal Boiling Point $\left(T_{\mathrm{b}}\right)$ of each FC

\begin{tabular}{|c|c|c|c|c|c|}
\hline & & $\left(E_{\eta} / R\right) \pm \sigma^{a}$ & $\left(E_{\eta} \pm \sigma^{a}\right)$ & & $T_{\mathrm{b}}$ \\
\hline fluid & $\ln \eta_{0} \pm \sigma^{a}$ & K & $\mathrm{J} \cdot \mathrm{mol}^{-1}$ & $M_{\mathrm{r}}$ & K \\
\hline $\mathrm{C}_{6} \mathrm{~F}_{14}$ & $-11.0 \pm 0.3$ & $1117 \pm 84$ & $9287 \pm 84$ & 337.9018 & 331.88 \\
\hline $\mathrm{C}_{7} \mathrm{~F}_{16}$ & $-11.2 \pm 0.4$ & $1262 \pm 121$ & $10492 \pm 121$ & 387.8894 & 355.00 \\
\hline $\mathrm{C}_{8} \mathrm{~F}_{18}$ & $-12.0 \pm 0.1$ & $1577 \pm 35$ & $13118 \pm 35$ & 437.8769 & 375.30 \\
\hline $\mathrm{C}_{9} \mathrm{~F}_{20}$ & $-12.1 \pm 0.2$ & $1716 \pm 73$ & $14265 \pm 73$ & 487.8644 & 398.65 \\
\hline $\mathrm{C}_{8} \mathrm{~F}_{17} \mathrm{Br}$ & $-12.1 \pm 0.6$ & $1778 \pm 185$ & $14783 \pm 185$ & 498.7926 & 415.15 \\
\hline $\mathrm{C}_{7} \mathrm{~F}_{14}$ & $-11.8 \pm 0.5$ & $1619 \pm 168$ & $13460 \pm 168$ & 349.9125 & 349.30 \\
\hline $\mathrm{C}_{10} \mathrm{~F}_{18}$ & $-13.5 \pm 0.1$ & $2456 \pm 35$ & $20418 \pm 35$ & 461.8983 & 415.20 \\
\hline $\mathrm{C}_{6} \mathrm{~F}_{6}$ & $-12.6 \pm 0.2$ & $1671 \pm 74$ & $13892 \pm 74$ & 185.9946 & 353.40 \\
\hline $\mathrm{C}_{7} \mathrm{~F}_{8}$ & $-11.4 \pm 0.1$ & $1321 \pm 12$ & $10980 \pm 12$ & 235.9821 & 377.07 \\
\hline
\end{tabular}

${ }^{a}$ Expanded uncertainty with an approximate $95 \%$ level of confidence.

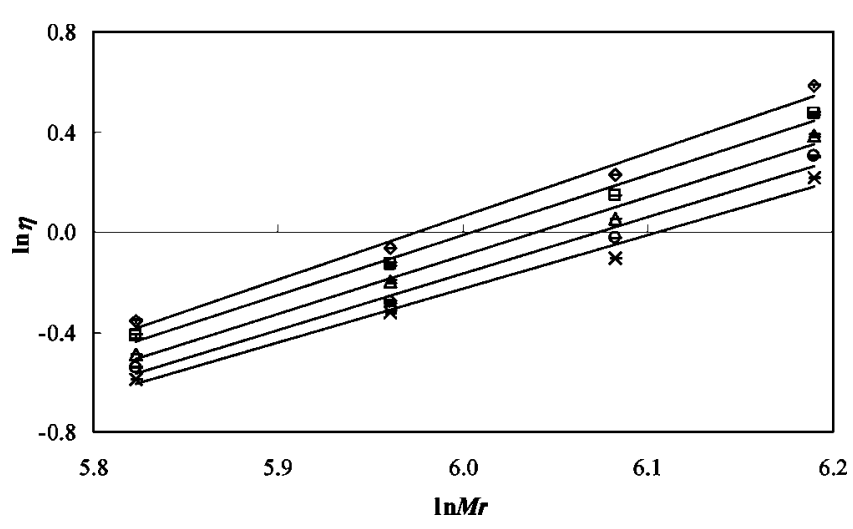

Figure 3. Linear relation of $\ln \eta$ as a function of $\ln M_{\mathrm{r}}$ for the $n$-perfluoroalkanes studied at each temperature: $\diamond, 298.15 \mathrm{~K}$; $\square, 303.15$ $\mathrm{K} ; \Delta, 308.15 \mathrm{~K} ; \bigcirc, 313.15 \mathrm{~K} ; \times, 318.15 \mathrm{~K}$.

The results of the activation energies obtained from the linear fit and the respective associated uncertainty at $95 \%$ confidence level ${ }^{32}$ are presented in Table 3 for each FC studied. This linear fit can be of substantial benefit for predicting FC viscosities at temperatures where experimental data are not available. As verified before for $n$-alkanes and linear polyethylene, ${ }^{33}$ the activation energy increases with chain length and/or molecular weight within the same family. The only family that does not follow this trend is the aromatic family. The methyl substitution in the aromatic ring leads to a decrease in the activation energy, probably due to an entropic effect that decreases the intermolecular interactions 


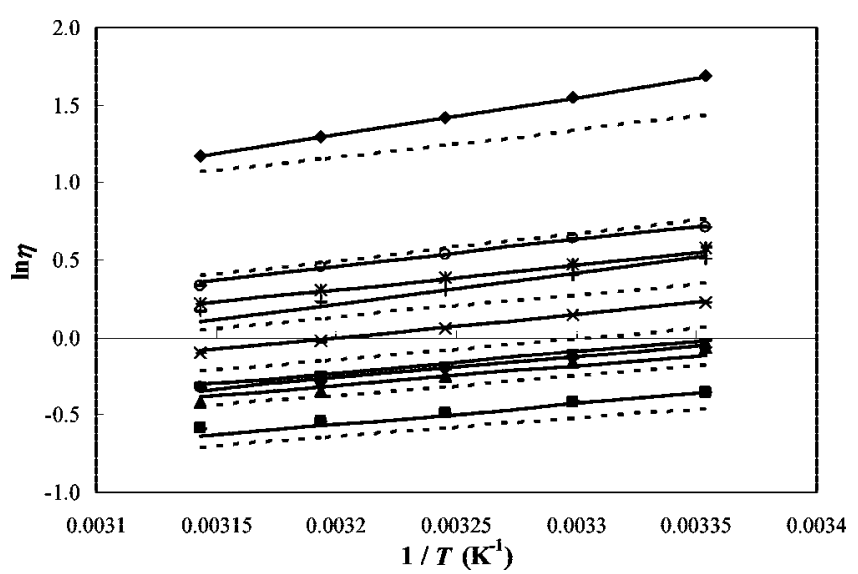

Figure 4. Viscosity dependence of temperature: $\mathbf{n}, \mathrm{C}_{6} \mathrm{~F}_{14} ; \bullet, \mathrm{C}_{7} \mathrm{~F}_{16} ; \times$, $\mathrm{C}_{8} \mathrm{~F}_{18} ; *, \mathrm{C}_{9} \mathrm{~F}_{20} ; \mathrm{O}, \mathrm{C}_{8} \mathrm{~F}_{17} \mathrm{Br} ;+, \mathrm{C}_{7} \mathrm{~F}_{14} ; \mathrm{C}_{10} \mathrm{~F}_{18} ; \boldsymbol{\Delta}, \mathrm{C}_{6} \mathrm{~F}_{6} ;-, \mathrm{C}_{7} \mathrm{~F}_{8}$. The single symbols represent the experimental data and the lines the Sastri-Rao ${ }^{20}$ correlation for each liquid fluorocompound (---, with Sastri-Rao original group contribution values $;^{20}-$, with group contribution values from this work).

between aromatic rings. Furthermore, the inclusion of a less electronegative bromide atom in the perfluorooctane leads to an increase in the activation energy, which arises from the dipole creation at the molecule that further promotes the intermolecular interactions. ${ }^{31}$

For the $n$-perfluoroalkane family, a correlation between the viscosity data and their molecular weight for all temperatures was observed, as depicted in Figure 3. Using this approach, it is thus possible to predict the dynamic viscosity of linear perfluoroalkanes when no experimental data are available.

Sastri-Rao ${ }^{20}$ Method. The Satri-Rao method (1992) ${ }^{20-22}$ is a group contribution method used to estimate low-temperature liquid viscosities. The pure liquid viscosity is related to its vapor pressure at each temperature using the normal boiling point as the reference point, as described by eq 2

$$
\eta=\eta_{\mathrm{B}} P_{\mathrm{vp}}^{-N}
$$

where $\eta(\mathrm{mPa} \cdot \mathrm{s})$ is the pure liquid viscosity; $\eta_{\mathrm{B}}(\mathrm{mPa} \cdot \mathrm{s})$ is the viscosity at the normal boiling point; $P_{\mathrm{vp}}(\mathrm{atm})$ is the vapor pressure of each liquid; and $N$ is a fitted index. For temperatures below the normal boiling point, Sastri and $\mathrm{RaO}^{20-22}$ proposed the following equation to determine the vapor pressure

$$
\begin{array}{r}
\ln P_{\mathrm{vp}}=\left(4.5398+1.0309 \ln T_{\mathrm{b}}\right) \cdot\left(1-\frac{\left(3-2 T / T_{\mathrm{b}}\right)^{0.19}}{T / T_{\mathrm{b}}}\right)- \\
0.38\left(3-2 T / T_{\mathrm{b}}\right)^{0.19} \ln \left(T / T_{\mathrm{b}}\right)
\end{array}
$$

where $T(\mathrm{~K})$ is the temperature of interest and $T_{\mathrm{b}}(\mathrm{K})$ is the normal boiling point of each liquid.

The contributions of the functional groups to $\eta_{\mathrm{B}}$ and $N$ are generally cumulative, but for compounds with more than one identical functional group, its contributions to $N$ should be taken only once unless otherwise mentioned. The $\eta_{\mathrm{B}}$ and $N$ are determined by the following eqs

$$
\begin{gathered}
\eta_{\mathrm{B}}=\sum \Delta \eta_{\mathrm{B}}+\sum \Delta \eta_{\mathrm{Bcor}} \\
N=0.2+\sum \Delta N+\sum \Delta N_{\text {cor }}
\end{gathered}
$$

The correlation between pure liquid viscosity and the vapor pressure of each liquid was applied for all the fluorocarbons and temperatures experimentally studied, as described by eqs 2 to 5. The normal boiling point of each liquid fluorocompound required to determine the vapor pressure was taken from the literature and is reported in Table $3 .^{29,34}$ The Sastri- $\mathrm{RaO}^{20-22}$ original group contribution values were used for the linear and perfluorodecalin fluorocompounds, although no contribution values were found for the aromatic perfluorocompounds and for the methyl group substitution in cyclic compounds. The average relative deviation found between the experimental data and the respective correlation with the original group contribution values ${ }^{20}$ is in the order of $12.0 \%$. The limited experimental viscosity data previously available were probably the main reason for the high relative deviations observed with the Sastri-Rao ${ }^{20}$ method. New group contribution values are here proposed as well as some original values for the aromatic perfluorocarbon family and for the $-\mathrm{CF}_{3}$ substitution in cyclic compounds such as the perfluoromethylcyclohexane. The experimental results, along with the Sastri- $\mathrm{RaO}^{20}$ correlation results, both with the original group contribution values ${ }^{20-22}$ (dashed lines) and the group contribution values proposed here (solid lines), are presented in Figure 4. The Sastri-Rao group contribution values for $\eta_{\mathrm{B}}$ and $N$ are presented and compared in Table 4 . The average relative deviation of the correlation using these new proposed values in respect to experimental data is $1.3 \%$. These new values for the group contribution parameters

\begin{tabular}{|c|c|c|c|c|}
\hline \multirow[b]{2}{*}{ group } & \multicolumn{2}{|c|}{ Sastri-Rao $(1992)^{20}$} & \multicolumn{2}{|c|}{ this work } \\
\hline & $\Delta \eta_{\mathrm{B}} /(\mathrm{mPa} \cdot \mathrm{s})$ & $\Delta N$ & $\Delta \eta_{\mathrm{B}} /(\mathrm{mPa} \cdot \mathrm{s})$ & $\Delta N$ \\
\hline nonring $-\mathrm{CF}_{3}$ & 0.210 & $\begin{array}{l}0.150 \text { for all } \\
n \text {-perfluorocompounds }\end{array}$ & 0.226 & $\begin{array}{l}0.189 \text { for } \\
n \text {-perfluorocompounds }\end{array}$ \\
\hline ring $-\mathrm{CF}_{3}$ & - & - & 0.226 & $\begin{array}{l}0.228 \text { for } \\
\text { cyclic perfluorocompounds }\end{array}$ \\
\hline ring $>\mathrm{CF}-$ & -0.170 & $\begin{array}{l}0.200 \text { for all } \\
\text { cyclic compounds }\end{array}$ & 0.009 & $\begin{array}{l}0.228 \text { for } \\
\text { cyclic perfluorocompounds }\end{array}$ \\
\hline$-\mathrm{CF}_{2} \mathrm{Br}$ & 0.210 & 0.000 & 0.137 & $\begin{array}{l}0.200 \text { for } \\
\text { perfluorooctylbromide }\end{array}$ \\
\hline$=\mathrm{CF}-$ & - & - & 0.076 & $\begin{array}{l}0.151 \text { for aromatic } \\
\text { perfluorocompounds }\end{array}$ \\
\hline$=\mathrm{C}\left(\mathrm{CF}_{3}\right)-$ & - & - & -0.004 & $\begin{array}{l}0.151 \text { for aromatic } \\
\text { perfluorocompounds }\end{array}$ \\
\hline
\end{tabular}
should allow the prediction of viscosities for members of the fluorocompoud family for which the experimental data are very scarce.

Table 4. Sastri-Rao $(1992)^{20}$ and This Work's Group Contribution Values for $\eta_{\mathrm{B}}$ and $N$ 


\section{Conclusions}

Original experimental dynamic viscosity data for $\mathrm{C}_{6} \mathrm{~F}_{14}$ to $\mathrm{C}_{9} \mathrm{~F}_{20} n$-perfluoroalkanes, two cyclic $\left(\mathrm{C}_{7} \mathrm{~F}_{14}\right.$ and $\left.\mathrm{C}_{10} \mathrm{~F}_{18}\right)$, two aromatic $\left(\mathrm{C}_{6} \mathrm{~F}_{6}\right.$ and $\left.\mathrm{C}_{7} \mathrm{~F}_{8}\right)$, and one $\alpha$-substituted fluorocompound $\left(\mathrm{C}_{8} \mathrm{~F}_{17} \mathrm{Br}\right)$ measured in the temperature range from (298.15 to 318.15) $\mathrm{K}$ using an Ubbelohde viscometer are presented. The FCs studied present higher viscosities than their alkane homologues, due to their higher molecular weight. Within the same family, the viscosity increases with the carbon number, and for the same number of carbon atoms, the viscosity increases from linear to aromatic to cyclic PFCs. Substitution of fluorine by the heavier atom bromine in the same chain molecule increases the viscosity. An Arrhenius-type behavior for the viscosity dependence with temperature was verified for all the studied FCs. A linear relationship between the viscosity and the molecular weight of $n$-perfluoroalkanes was also observed. The Sastri-Rao method ${ }^{20}$ was used to correlate viscosity as a function of temperature using functional group contribution values for the studied fluorocompounds. New group contribution values were proposed leading to a decrease of the average relative deviation from $12.0 \%$ to $1.3 \%$ with respect to the experimental viscosity data.

\section{Literature Cited}

(1) Riess, J. G. Oxygen Carriers ("Blood Substitutes") - Raison d'Etre, Chemistry, and Some Plhysiology. Chem. Rev. 2001, 101, 2797-2919.

(2) Dias, A. M. A.; Bonifácio, R. P.; Marrucho, I. M.; Pádua, A. A. H.; Costa Gomes, M. F. Solubility of Oxygen in $n$-hexane and in $n$-perfluorohexane. Experimental Determination and Prediction by Molecuar Simulation. Phys. Chem. Chem. Phys. 2003, 5, 543-549.

(3) Dias, A. M. A.; Freire, M. G.; Coutinho, J. A. P.; Marrucho, I. M. Solubility of Oxygen in Liquid Perfluorocarbons. Fluid Phase Equilib. 2004, 222-223, 325-330.

(4) Dias, A. M. A.; Pàmies, J. C.; Coutinho, J. A. P.; Marrucho, I. M.; Vega, L. F. SAFT Modeling of the Solubility of Gases in Perfluoroalkanes. J. Phys. Chem. B 2004, 108, 1450-1457.

(5) Dias, A. M. A.; Gonçalves, C. M. B.; Legido, J. L.; Coutinho, J. A. P.; Marrucho, I. M. Solubility of oxygen in substituted perfluorocarbons. Fluid Phase Equilib. 2005, 238, 7-12.

(6) Freire, M. G.; Dias, A. M. A.; Coelho, M. A. Z.; Coutinho, J. A. P.; Marrucho, I. M. Enzymatic Method for Determining Oxygen Solubility in Perfluorocarbon Emulsions. Fluid Phase Equilib. 2005, 231, 109113.

(7) Dias, A. M. A.; Pàmies, J. C.; Vega, L. F.; Coutinho, J. A. P.; Marrucho, I. M. Modelling the Solubility of Gases in Saturated and Substituted Perfluoroalkanes. Pol. J. Chem. 2006, 80, 143-152.

(8) Dias, A. M. A.; Carrier, H.; Daridon, J. L.; Pàmies, J. C.; Vega, L. F. Coutinho, J. A. P.; Marrucho, I. M. Vapor-Liquid Equilibrium of Carbon Dioxide-Perfluoroalkane Mixtures: Experimental Data and SAFT Modeling. Ind. Eng. Chem. Res. 2006, 45, 2341-2350.

(9) Freire, M. G.; Dias, A. M. A.; Coelho, M. A. Z.; Coutinho, J. A. P.; Marrucho, I. M. Aging Mechanisms in Perfluorocarbon Emulsions using Image Analysis. J. Colloid Interface Sci. 2005, 286, 224-232.

(10) Hall, C. S.; Lanza, G. M.; Rose, J. H.; Kaufman, R. J.; Fuhrhop, R. W.; Handley, S. H.; Waters, K. R.; Miller, J. G.; Wickline, S. A. Experimental Determination of Phase Velocity of Perfluorocarbons: Application to Targeted Contrast Agents. IEEE T. Ultrason. Ferr. 2000, 47, 75-84.

(11) Dumont, E.; Delmas, H. Mass Transfer Enhancement of Gas Absorption in Oil-in-Water Systems: a Review. Chem. Eng. Process. 2003, 42, 419-438.

(12) Amaral, P. F. F.; Freire, M. G.; Rocha-Leão, M. H. M.; Marrucho I. M.; Coutinho, J. A. P.; Coelho, M. A. Z. Optimization of Oxygen Mass Transfer in a Multiphase Bioreactor with Perfluorodecalin as a Second Liquid Phase. Biotechnol. Bioeng. 2007, DOI:10.1002/ bit.21640.
(13) Freire, M. G.; Razzouk, A.; Mokbel, I.; Jose, J.; Marrucho, I. M.; Coutinho, J. A. P. Solubility of Hexafluorobenzene in Aqueous Salt Solutions from (280 to 340) K. J. Chem. Eng. Data 2005, 50, 237242.

(14) Dias, A. M. A.; Gonçalves, C. M. B.; Caço, A. I.; Santos, L. M. N. B. F.; Piñeiro, M. M.; Vega, L. F.; Coutinho, J. A. P.; Marrucho, I. M. Densities and Vapor Pressures of Highly Fluorinated Compounds. J. Chem. Eng. Data 2005, 50, 1328-1333.

(15) Freire, M. G.; Carvalho, P. J.; Queimada, A. J.; Marrucho, I. M.; Coutinho, J. A. P. Surface Tension of Liquid Fluorocompounds. J. Chem. Eng. Data 2006, 51, 1820-1824.

(16) Grosse, A. V.; Cady, G. H. Properties of Fluorocarbons. Ind. Eng. Chem. 1947, 39, 367-374.

(17) Stiles, V. E.; Cady, G. H. Properties of Perfluoro- $n$-hexane and Perfluoro-2-methylpentane. J. Am. Chem. Soc. 1952, 74, 3771-3773.

(18) Haszeldine, R. N.; Smith, F. Organic Fluorides. Part VI. The Chemical and Physical Properties of Certain Fluorocarbons. J. Chem. Soc. 1951, 603-608.

(19) Freire Martins, M. G. Aeration and Extraction in Multiphase Biological Reactors, PhD Thesis in Chemical Engineering, University of Aveiro, Aveiro, Portugal, 2007.

(20) Sastri, S. R. S.; Rao, K. K. A new method for predicting saturated liquid viscosity at temperatures above the normal boiling point. Chem. Eng. J. 1992, 50, 9-25.

(21) Satri, S. R. S.; Rao, K. K. A new method for predicting saturated liquid viscosity at temperatures above the normal boiling point. Fluid Phase Equilib. 2000, 175, 311-323.

(22) Poling, B. E.; Prausnitz, J. M.; O'Connel, J. P. The Properties of Gases and Liquids, 5th ed.; McGraw-Hill: New York, 2001.

(23) Gaonkar, A.; Newman, R. The Effect of Wettability of Wilhelmy Plate and Du Nouy Ring on Interfacial Tension Measurements in Solvent Extraction Systems. J. Colloid Interface Sci. 1984, 98, 112-119.

(24) Goebel, A.; Lunkenheimer, K. Interfacial Tension of the Water $/ n$ Alkane Interface. Langmuir 1997, 13, 369-372.

(25) Chirico, R. D.; Frenkel, M.; Diky, V. V.; Marsh, K. N.; Wilhoit, R. C. ThermoMLsAn XML-Based Approach for Storage and Exchange of Experimental and Critically Evaluated Thermophysical and Thermochemical Property Data. 2. Uncertainties. J. Chem. Eng. Data 2003, 48, 1344-1359.

(26) The NIST Reference on Constants, Units, and Uncertainty at http:// physics.nist.gov/cuu/.

(27) Dias, A. M. A.; Caço, A. I.; Coutinho, J. A. P.; Santos, L. M. N. B. F.; Piñeiro, M. M.; Vega, L. F.; Gomes, M. F. C.; Marrucho, I. M. Thermodynamic Properties of Perfluoro- $n$-octane. Fluid Phase Equilib. 2004, 225, 39-47.

(28) Dias, A. M. A. Gas Solubilities in Blood Substitutes, PhD Thesis in Chemical Engineering, University of Aveiro, Aveiro, Portugal, 2005.

(29) Afeefy, H. Y.; Liebman, J. F.; Stein, S. E. Neutral Thermochemical Data in NIST Chemistry WebBook, NIST Standard Reference Database Number 69; Linstrom, P. J., Mallard, W. G., Eds.; National Institute of Standards and Technology: Gaithersburg, MD, 20899, June 2005, (http://webbook.nist.gov).

(30) Dunlop, P. J. Viscosities of a Series of Gaseous Fluorocarbons at 25 ${ }^{\circ} \mathrm{C}$. J. Chem. Phys. 1994, 100, 3149-3151.

(31) Freire, M. G.; Gomes, L.; Santos, L. M. N. B. F.; Marrucho, I. M.; Coutinho, J. A. P. Water Solubility in Linear Fluoroalkanes Used in Blood Substitute Formulations. J. Phys. Chem. B 2006, 110, 2292322929.

(32) Miller, J. C.; Miller, J. N. Statistical for Analytical Chemistry, 3rd ed.; PTR Prentice Hall: Chichester, 1993.

(33) Pearson, D. S.; Ver Strate, G.; von Meerwall, E.; Schilling, F. C. Viscosity and Self-Diffusion Coefficient of Linear Polyethylene. Macromolecules 1987, 20, 1133-1141.

(34) Apollo Scientific, Supplier of Fluorochemicals, at http://www. apolloscientific.co.uk/index.asp.

Received for review October 30, 2007. Accepted November 30, 2007. This work was supported by FEDER and Fundação para a Ciência e a Tecnologia (Project POCI/EQU/44427/2002). M.G. Freire acknowledges the financial support from Fundação para a Ciência e a Tecnologia through her PhD scholarship (SFRH/BD/14134/2003).

JE700632Z 